\title{
Risk factors of knee osteoarthritis: A case-control study
}

\author{
Nasrin Moghimi ${ }^{1}$, Khaled Rahmani ${ }^{2}$, Ali Delpisheh ${ }^{3}$, \\ Afshin Saidi ${ }^{4}$, Namam Ali Azadi ${ }^{5}$, Abdorrahim Afkhamzadeh ${ }^{6}$
}

\begin{abstract}
Background and Objective: Knee osteoarthritis is one of the most common rheumatologic problems. To investigate risk factors related to the knee osteoarthritis a case-control study was performed using cases diagnosed in the Community Oriented Program for Control of Rheumatic Diseases (COPCORD) study, stage I. Methods: Using data from the 2012 COPCORD study, stage-I that was conducted in Sanandaj, northwestern of Iran, we runned a case-control study in 2014-2015. Cases were 700 knee osteoarthritis using American College of Rheumatology (ACR) criteria, frequency matched with 700 healthy controls that were randomly selected from the general population.

Results: In multivariate analysis, statistical significant relation was observed between knee OA and some studied factors such as body mass index $(P<0.001)$, lodging (living in highland vs. plain) $(P<0.001)$, type of used toilet (regular vs. toilet) $(P<0.001)$, history of using high-heeled shoes $(>3 \mathrm{~cm})(P=0.005)$, history of knee Injury $(P=0.04)$, history of lower limb fracture $(P=0.02)$, Number of pregnancies $(P<0.001)$ and history of pain and swelling (lasting for one months) $(P=0.04)$.

Conclusions: Living in highland area, using regular toilet, having knee injury and lower limb fracture in the past were most significant associated factors with occurrence of knee osteoarthritis.
\end{abstract}

KEYWORDS: Risk factors, Knee osteoarthritis, COPCORD study.

doi: https://doi.org/10.12669/pjms.35.3.277

How to cite this:

Moghimi N, Rahmani K, Delpisheh A, Saidi A, Azadi NA, Afkhamzadeh A. Risk factors of knee osteoarthritis: A case-control study. Pak $J$ Med Sci. 2019;35(3):636-640. doi: https://doi.org/10.12669/pjms.35.3.277

This is an Open Access article distributed under the terms of the Creative Commons Attribution License (http://creativecommons.org/licenses/by/3.0), which permits unrestricted use, distribution, and reproduction in any medium, provided the original work is properly cited.

\section{INTRODUCTION}

Osteoarthritis (OA) is the most widespread rheumatic illness in human populations leading to chronic pains and severe disabilities worldwide. ${ }^{1}$ Knee is the most common site of the disease and OA, which causes physical disability in elderly. ${ }^{2}$ The OA basically occurs by underlying causes such as previous fractures, bone injuries, infections,

\footnotetext{
Correspondence:

Dr. Abdorrahim Afkhamzadeh,

Social Determinants of Health Research Center,

Research Institute for Health Development,

Kurdistan University of Medical Sciences,

Sanandaj, Iran.

Email: afkhama@gmail.com

* Received for Publication:

December 29, 2018

* Revision Received:

* Revision Accepted:
}

rheumatoid arthritis, tumors, congenital and metabolic disorders. ${ }^{3,4}$

Community Oriented Program for Control of Rheumatic Diseases (COPCORD) has three stages including determination of prevalence of rheumatic disorders and identification of risk factors; training of primary health-care physicians, paramedical professionals, and improving health care and environmental etiologic researches for rheumatic diseases. ${ }^{5}$ The stage I of Kurdistan COPCORD was conducted during 2012 and its results including prevalence of knee problems has been published in $2015 .^{6}$

Since knee OA is one of the common diseases, is responsible for higher morbidity, particularly in women and in the second half of human life, when the quality of life for patients with knee OA is important issue. 3,7 In terms of importance and necessity of the present study, almost one in five 
persons aged over 15 years in Kurdistan area, had knee complaints, ${ }^{6}$ whilst the corresponding rate was about one in six in Tehran capital as national data. ${ }^{5}$ So, the present study aimed to determine risk factors of knee osteoarthritis in Kurdistan province western Iran.

\section{METHODS}

This case-control study was conducted in Sanandaj city during 2014-2015, the center of Kurdistan province. The ethnicity of study setting is Kurdish, a subgroup of the Caucasians with total population of 311,446 living in 81,380 households.

Cases were those who were diagnosed as knee OA using ACR criteria in Sanandaj COPCORD study. ${ }^{6}$ Controls were also selected from those who were diagnosed healthy and those who had no knee OA. The ACR criteria were used for diagnosing of knee OA, knee pain with at least three out of six criteria in case group. Overall, cases were 700 persons with Knee OA, randomly selected from 1099 knee OA patients diagnosed at the first phase of the COPCORD study. One control (healthy people) was chosen for each case.

The method of data gathering was interview with participants. A valid and reliable questionnaire by the Tehran Rheumatology Research Center was used for data collection. ${ }^{8}$ The interviews were controlled by a rheumatologist advisor and all samples were received a regular quality control visit from the project manager.

Data were analyzed using SPSS version 19. First, univariate analysis was used, then for factors that statistically were significant in univariate analysis and also other variables with $\mathrm{P}<0.1$ were entered in the multivariate analysis, logistic regression model.

\section{RESULTS}

Mean age and standard deviation of case and control groups were $51.8 \pm 15.2$ and $52.5 \pm 15.1$ years, respectively $(\mathrm{P}=0.4)$. Sixty percent of participants in each group were female. Mean and standard deviation of investigated quantitative variables in two studied groups and its relation with knee OA were detailed in Table-I.

Association between other qualitative variables and knee OA are presented in Table-II. Regression logistic results including the values of $\mathrm{P}$ value, odds ratio and corresponding 95\% confidence intervals for each factor are summarized in Table-III.
As shown in Table-III, the chance of knee OA occurrence in persons which lived in highland is significantly $5.67(4.40-7.31)$ times higher than those lived in plain area. Other factors that had strength relation with knee OA were toilet type use (OR:2.28, CI:1.47 - 3.55), having knee injury in the past (OR:1.74, CI:1.03 - 2.96) and persons with lower limb fracture in the past (OR:1.64, CI:1.07- 2.53).

\section{DISCUSSION}

In this study potential risk factors related to the knee OA were evaluated among urban population of Sanandaj city, Kurdistan Iran. In fact, the study was the stage III of previous COPCORD that has been designed and conducted in 2012. ${ }^{6}$ According to the study results, although not significant, but the chance of getting knee $\mathrm{OA}$ is increased by increasing age. This finding is compatible with the results of previous studies. ${ }^{8,9}$

In other previous studies, the female gender was reported as main risk factor for knee OA and other musculoskeletal disease and the difference in gender distribution may be due to sensitivity of cartilage tissue to sex hormones as knee cartilage volume is higher in males than in females, ${ }^{10-12}$ but we could not asses the relationship between sex and knee OA due to individually matching cases and controls.

Several national ${ }^{13}$ and international studies ${ }^{14-18}$ have already indicated the effects of BMI on

Table-I: Association between potential risk factors (quantitative variables) and knee osteoarthritis.

\begin{tabular}{|c|c|c|c|c|}
\hline Variables & Group & Mean & $S D$ & $P$ value \\
\hline \multirow{2}{*}{$\begin{array}{l}\text { Body Mass } \\
\text { Index }\end{array}$} & Case & 28.8 & 4.3 & \multirow[t]{2}{*}{$<0.001$} \\
\hline & Control & 27.3 & 4.7 & \\
\hline \multirow{2}{*}{$\begin{array}{l}\text { Daily squatting } \\
\text { or crouching (min*) }\end{array}$} & Case & 24.1 & 2.7 & \multirow[t]{2}{*}{0.7} \\
\hline & Control & 23.7 & 3.3 & \\
\hline \multirow{2}{*}{$\begin{array}{l}\text { Daily chair } \\
\text { sitting (minutes) }\end{array}$} & Case & 168.6 & 24.3 & \multirow[t]{2}{*}{0.6} \\
\hline & Control & 170.4 & 25.2 & \\
\hline \multirow{2}{*}{$\begin{array}{l}\text { Daily kneeling } \\
\text { (minutes) }\end{array}$} & Case & 15.5 & 2.1 & \multirow[t]{2}{*}{0.8} \\
\hline & Control & 14.8 & 1.7 & \\
\hline \multirow{2}{*}{$\begin{array}{l}\text { Using high-heeled } \\
\text { shoes }(>3 \mathrm{~cm}) \text { in } \\
\text { the past }\end{array}$} & Case & 4.6 & 1.7 & \multirow[t]{2}{*}{0.004} \\
\hline & Control & 4.2 & 1.3 & \\
\hline \multirow[t]{2}{*}{ N. of pregnancies } & Case & 3.9 & 4.3 & \multirow[t]{2}{*}{$<0.001$} \\
\hline & Control & 3.0 & 3.7 & \\
\hline \multirow{2}{*}{$\begin{array}{l}\text { Duration of } \\
\text { hypertension (years) }\end{array}$} & Case & 11.3 & 8.0 & \multirow[t]{2}{*}{$<0.001$} \\
\hline & Control & 6.4 & 5.8 & \\
\hline \multirow{2}{*}{$\begin{array}{l}\text { Duration of other } \\
\text { chronic diseases } \\
\text { (years) }\end{array}$} & Case & 17.6 & 12.6 & \multirow[t]{2}{*}{$<0.001$} \\
\hline & Control & 7.5 & 7.4 & \\
\hline
\end{tabular}

${ }^{*}$ Minute. 
Risk factors of knee osteoarthritis

Table-II: Association between potential risk factors (qualitative variables) and knee osteoarthritis.

\begin{tabular}{|c|c|c|c|c|}
\hline Factors & Case, $n(\%)$ & Control, $n(\%)$ & P value & OR $(95 \% C I)^{*}$ \\
\hline Exercise & & & 0.004 & $1.56(1.15-2.12)$ \\
\hline Yes & $119(59.5)$ & $81(40.5)$ & & \\
\hline No & $581(48.4)$ & $619(51.6)$ & & \\
\hline History of using high-heeled shoes $(>3 \mathrm{~cm})$ & & & 0.008 & $1.42(1.09-1.85)$ \\
\hline Yes & $163(57.0)$ & $123(43.0)$ & & \\
\hline No & $537(48.2)$ & $577(51.8)$ & & \\
\hline Lodging & & & $<0.001$ & $5.24(4.13-6.64)$ \\
\hline living in highland area & $554(65.3)$ & $294(34.7)$ & & \\
\hline living in plain area & $146(26.4)$ & $406(73.6)$ & & \\
\hline Cigarette smoking & & & 0.08 & $1.3(0.97-1.72)$ \\
\hline Yes & $124(55.3)$ & $100(44.7)$ & & \\
\hline No & $576(48.9)$ & $600(51.1)$ & & \\
\hline History of knee injury & & & $<0.001$ & $0.41(0.2-0.6)$ \\
\hline Yes & $60(69.8)$ & $26(30.2)$ & & \\
\hline No & $640(48.7)$ & $674(51.3)$ & & \\
\hline History of lower limb fracture & & & 0.001 & $0.55(0.30-0.80)$ \\
\hline Yes & 76 (63.3) & $44(36.7)$ & & \\
\hline No & $624(48.8)$ & $656(51.2)$ & & \\
\hline History of pain and swelling (lasting for one month) & & & 0.007 & $1.34(1.08-1.65)$ \\
\hline Yes & $423(53.1)$ & $373(46.9)$ & & \\
\hline No & $277(45.9)$ & $327(54.1)$ & & \\
\hline Menopause & & & 0.032 & $1.36(1.0-1.70)$ \\
\hline Yes & $268(53.1)$ & $237(46.9)$ & & \\
\hline No & $161(45.5)$ & $193(54.5)$ & & \\
\hline Familial history of knee problems & & & $<0.001$ & $0.05(1.1-1.4)$ \\
\hline Yes & $280(56.3)$ & $217(43.7)$ & & \\
\hline No & $360(44.7$ & $446(55.3)$ & & \\
\hline Diabetes & & & 0.004 & $0.59(0.41-0.81)$ \\
\hline Yes & $90(61.2)$ & $57(38.8)$ & & \\
\hline No & $601(48.4)$ & $641(51.6)$ & & \\
\hline Hypertension & & & $<0.001$ & $0.60(0.4-0.7)$ \\
\hline Yes & $177(59.4)$ & $121(40.6)$ & & \\
\hline No & $506(46.9)$ & $574(53.1)$ & & \\
\hline Other chronic diseases & & & 0.09 & $0.80(0.6-1.0)$ \\
\hline Yes & $198(53.8)$ & $170(46.2)$ & & \\
\hline No & $495(48.3)$ & $529(51.7)$ & & \\
\hline Type of toilet use & & & 0.07 & $1.42(0.97-2.08)$ \\
\hline Regular & $650(50.7)$ & $631(49.3)$ & & \\
\hline Toilet & $50(42.0)$ & $69(58.0)$ & & \\
\hline
\end{tabular}

*OR: Odds Ratio, CI: Confidence Interval.

occurrence of knee OA. In study conducted by El Ayoubi et al. showed that obesity, overweight and area of residence are significant risk factors for knee OA. ${ }^{19}$ The present study confirms this finding $(P<0.001)$. Even though in Dahaghin study, this association was borderline. ${ }^{13}$ However, many studies have confirmed the effect of overweight and obesity on knee OA. ${ }^{7,20}$ A recent meta-analysis found the pooled odds ratio for developing knee OA was 2.63 for obese subjects compared to normal weight controls. ${ }^{21}$
This study showed that people, who live in highland areas, suffered more from knee OA. Yoshimura et al have already reported that the risk of knee OA in people who were living in mountainous regions was two-fold higher than those who lived in the forest and beach areas. Many previous studies have suggested climbing, long time downing and upping of stairs, job and life activities as risk factors for osteoarthritis specially knee OA. ${ }^{22-25}$ Based on the results, living in highland areas that lead to daily climbing up 
Nasrin Moghimi et al.

Table-III: Potential risk factors related to Knee OA (Logistic regression results).

\begin{tabular}{lcc}
\hline Variable & OR $(95 \% \text { CI })^{*}$ & P value \\
\hline Age & $1.01(0.99-1.01)$ & 0.1 \\
Body Mass Index & $1.09(1.06-1.12)$ & $<0.001$ \\
Lodging (living in highland vs. plain) & $5.67(4.40-7.31)$ & $<0.001$ \\
Cigarette smoking & $1.22(0.99-1.52)$ & 0.06 \\
Exercise & $1.22(0.86-1.73)$ & 0.3 \\
Toilet type use (regular vs. toilet) & $2.28(1.47-3.55)$ & $<0.001$ \\
History of using high-heeled shoes $(>3 \mathrm{~cm})$ & $1.53(1.14-2.07)$ & 0.005 \\
History of knee injury & $1.74(1.03-2.96)$ & 0.04 \\
Familial history of knee problems & $1.26(0.98-1.62)$ & 0.06 \\
History of lower limb fracture & $1.64(1.07-2.53)$ & 0.02 \\
History of pain and swelling (lasting for 1 months) & $1.31(1.01-1.70)$ & 0.04 \\
N. of pregnancies & $1.08(1.05-1.12)$ & $<0.001$ \\
Diabetes & $1.19(0.80-1.80)$ & 0.4 \\
Hypertension & $1.30(0.95-1.80)$ & 0.1 \\
Other chronic disease & $1.03(0.80-1.36)$ & 0.8 \\
\hline
\end{tabular}

and down from steep and high places was most important risk factor for knee $\mathrm{OA}(\mathrm{OR}=5.67)$ in studied subjects. A reason for this association can be that the setting of the study, Sanandaj, was located in the mountainous area and more of the city neighborhoods are not geographically plain, so that people living in highland neighborhoods of the city, inevitably had to daily walk up and down for their activities. Despite of this fact, it seems this important factor, need to be assessed in further studies.

In the present study, smoking was not associated with knee OA $(P=0.06)$. This finding is very controversial. Although study results of Haq et al is compatible with our finding, ${ }^{26}$ but many researchers have reported positive effects of smoking as a protective factor for knee OA. ${ }^{27,28}$

The regular toilet using was another significant factor for knee OA. Dahaghin et al. in Tehran found same result and they showed that using the toilet reduces the risk of osteoarthritis, ${ }^{13}$ while our result was not similar to Zeng et al. study. ${ }^{9}$ Indeed, majority of population in our studied area are now using regular toilet due to cultural reasons and this factor can be modified as preventable risk factor with suitable intervention.

History of knee injury and lower limb fracture in the past were two other significant factors for knee OA in the present study, which has already been confirmed. ${ }^{29}$ The lower limb fracture had relationship with knee OA. ${ }^{7}$

Limitations of the study: Although, the study has many advantages such as adequate sample size, methodological design, controlling for potential confounders using logistic regression model and also presence of expert team, but our results like any other case control design may be affected from recall bias in measuring the exposures and also inability to assess all known and unknown exposures for knee OA such as nutritional and genetic factors.

\section{CONCLUSIONS}

Based on results of this study that was conducted in Sanandaj, the center of Kurdistan province in Iran, living in highland areas, using regular toilet, having history of knee injury and lower limb fracture, higher BMI, using high-heeled shoes in the past, having pain and swelling (lasting for one month) in past years and increasing in the number of pregnancies were recognized as risk factors for knee osteoarthritis.

Acknowledgements: The authors would like to thank all patients for collaboration in data collection. This study was supported by the AsiaPacific League of Associations for Rheumatology (APLAR). The funding of this work was provided by the APLAR grant.

\section{REFERENCES}

1. Cooper C, Javaid MK, Arden N. Epidemiology of osteoarthritis. Atlas of osteoarthritis: Springer; 2014. p. 21-36. doi: 10.1007/9781-910315-16-3_2

2. Cross M, Smith E, Hoy D, Nolte S, Ackerman I, Fransen M, et al. The global burden of hip and knee osteoarthritis: estimates from the global burden of disease 2010 study. Ann Rheum Dis. 2014;73(7):1323-1330. doi: 10.1136/annrheumdis-2013-204763

3. Moskowitz RW. Osteoarthritis: diagnosis and medical/surgical management: Lippincott Williams \& Wilkins; 2007. 
4. Samson DJ, Grant MD, Ratko TA, Bonnell CJ, Ziegler KM, Aronson N. Treatment of primary and secondary osteoarthritis of the knee. Evid Rep Technol Assess (Full Rep). 2007;157(157):1-157.

5. Davatchi F, Jamshidi A-R, Banihashemi AT, Gholami J, Forouzanfar $\mathrm{MH}$, Akhlaghi $\mathrm{M}$, et al. WHO-ILAR COPCORD study (stage 1, urban study) in Iran. J Rheumatol. 2008;35(7):1384-1390.

6. Moghimi N, Davatchi F, Rahimi E, Saidi A, Rashadmanesh N, Moghimi S, et al. WHO-ILAR COPCORD study (stage 1, urban study) in Sanandaj, Iran. Clin Rheumatol. 2015;34(3):535-543. doi: 10.1007/s10067-013-2430-0

7. Corti MC, Rigon C. Epidemiology of osteoarthritis: prevalence, risk factors and functional impact. Aging Clin Exp Res. 2003;15(5):359-363. doi: 10.1007/BF03327356

8. Du H, Chen SL, Bao CD, Wang XD, Lu Y, Gu YY, et al. Prevalence and risk factors of knee osteoarthritis in Huang$\mathrm{Pu}$ District, Shanghai, China. Rheumatol Int. 2005;25(8):585590. doi: $10.1007 /$ s00296-004-0492-7

9. Zeng QY, Zang CH, Li XF, Dong HY, Zhang AL, Lin L. Associated risk factors of knee osteoarthritis: A population survey in Taiyuan, China. Chin Med J (Engl). 2006;119(18):1522-1527.

10. Gielis WP, Welsing PMJ, van Spil WE, Runhaar J, Weinans $\mathrm{HH}$, de Jong PA. A sex-specific association between incident radiographic osteoarthritis of hip or knee and incident peripheral arterial calcifications: Eight-year prospective data from CHECK. Osteoarthritis Cartilage. 2017;25(11):1814-1821. doi: 10.1016/j.joca.2017.07.016

11. Srikanth VK, Fryer JL, Zhai G, Winzenberg TM, Hosmer D, Jones G. A meta-analysis of sex differences prevalence, incidence and severity of osteoarthritis. Osteoarthritis Cartilage. 2005;13(9):769-781. doi: 10.1016/j.joca.2005.04.014

12. Teichtahl A, Wluka A, Proietto J, Cicuttini F. Obesity and the female sex, risk factors for knee osteoarthritis that may be attributable to systemic or local leptin biosynthesis and its cellular effects. Med Hypotheses. 2005;65(2):312-315. doi: 10.1016/j.mehy.2005.02.026

13. Dahaghin S, Tehrani-Banihashemi S, Faezi S, Jamshidi A, Davatchi F. Squatting, sitting on the floor, or cycling: Are lifelong daily activities risk factors for clinical knee osteoarthritis? Stage III results of a community-based study. Arthritis Care Res. 2009;61(10):1337-1342. doi: 10.1002/art.24737

14. Berenbaum F, Eymard F, Houard X. Osteoarthritis, inflammation and obesity. Curr Opin Rheumatol. 2013;25(1):114-118. doi 10.1097/BOR.0b013e32835a9414

15. Ezumi MW, Amrah SS, Suhaimi A, Mohsin S. Evaluation of the female reproductive toxicity of aqueous extract of Labisia pumila var. alata in rats. Indian J Pharmacol. 2007;39(1):30-32. doi: 10.4103/0253-7613.30760

16. Irshad K, Shafi R, Afial MN. Correlation of osteoarthritis with BMI, age and gender differences in a tertiary care hospital in Pakistan. Rawal Med J. 2014;39(1):10-14.

17. Ismail AI, Al-Abdulwahab AH, Al-Mulhim AS. Osteoarthritis of knees and obesity in Eastern Saudi Arabia. Saudi Med J. 2006;27(11):1742-1744

18. Kim J, Song YW, Lee J-C, Sheen D, Park N-G, Lee YJ, et al. The study of risk factors for symptomatic knee osteoarthritis in Korea. J Korean Rheum Assoc. 2008;15(2):123-130. doi: 10.4078/ jkra.2008.15.2.123

19. El Ayoubi N, Chaaya M, Mahfoud Z, Habib RR, Uthman I, Slim ZN. Risk factors for incident symptomatic knee osteoarthritis: A population-based case control study in Lebanon. Int J Rheum Dis. 2013;16(2):211-218. doi: 10.1111/1756-185x.12047

20. Ding C, Martel-Pelletier J, Pelletier J-P, Abram F, Raynauld J-P, Cicuttini F, et al. Meniscal tear as an osteoarthritis risk factor in a largely non-osteoarthritic cohort: A cross-sectional study. J Rheumatol. 2007;34(4):776-784.

21. Blagojevic M, Jinks C, Jeffery A, Jordan K. Risk factors for onset of osteoarthritis of the knee in older adults: A systematic review and meta-analysis. Osteoarthritis Cartilage. 2010;18(1):24-33. doi: 10.1016/j.joca.2009.08.010
22. Kalichman L, Magram I, Reitblat T. AB0786 Knee Osteoarthritis and Functional Changes in Ankle Joint and Achilles Tendon. Ann Rheum Dis. 2014;73(Suppl 2):1064. doi: 10.1136/ annrheumdis-2014-eular.1620

23. Kong L, Wang L, Meng F, Cao J, Shen Y. Association between smoking and risk of knee osteoarthritis: A systematic review and meta-analysis. Osteoarthritis Cartilage. 2017;25(6):809-816. doi: 10.1016/j.joca.2016.12.020

24. Verbeek J, Mischke C, Robinson R, Ijaz S, Kuijer P, Kievit A, et al. Occupational exposure to knee loading and the risk of osteoarthritis of the knee: A systematic review and a doseresponse meta-analysis. Saf Health Work. 2017;8(2):130-142. doi: 10.1016/j.shaw.2017.02.001

25. Yoshimura N, Kinoshita H, Hori N, Nishioka T, Ryujin M, Mantani Y, et al. Risk factors for knee osteoarthritis in Japanese men: A case-control study. Modern Rheumatol. 2006;16(1):24-29.

26. Haq SA, Davatchi F, Dahaghin S, Islam N, Ghose A, Darmawan $\mathrm{J}$, et al. Development of a questionnaire for identification of the risk factors for osteoarthritis of the knees in developing countries. A pilot study in Iran and Bangladesh. An ILARCOPCORD phase III study. Int J Rheum Dis. 2010;13(3):203-214. doi: 10.1111/j.1756-185X.2010.01529.x

27. Felson DT, Zhang Y, Hannan MT, Naimark A, Weissman B, Aliabadi $\mathrm{P}$, et al. Risk factors for incident radiographic knee osteoarthritis in the elderly. The Framingham Study. Arthritis Rheum. 1997;40(4):728-733. doi: 10.1002/art.1780400420

28. Järvholm B, Lewold S, Malchau H, Vingard E. Age, bodyweight, smoking habits and the risk of severe osteoarthritis in the hip and knee in men. Eur J Epidemiol. 2005;20(6):537-542. doi: 10.1007/ s10654-005-4263-x

29. Vuolteenaho K, Koskinen A, Moilanen E. Leptin-a link between obesity and osteoarthritis. Applications for prevention and treatment. Basic Clin Pharmacol Toxicol. 2014;114(1):103-108. doi: $10.1111 /$ bcpt.12160

\section{Author's Contributions:}

NM: Study design, manuscript writing and editing of manuscript. KhR and AD: Manuscript writing and editing of manuscript. AS: Data collection and manuscript writing and editing. NAA: Participating in data analysis and manuscript writing and editing. AA: Statistical analysis, manuscript writing, review and final approval of manuscript.

\section{Authors:}

1. Nasrin Moghimi (MD).

Assistant Professor, Department of Rheumatology,

2. Khaled Rahmani (PhD).

Assistant Professor of Epidemiology,

Department of Community Medicine,

3. Ali Delpisheh (PhD, Postdoc).

Professor of Clinical Epidemiology,

Ilam University of Medical Sciences,

Ilam, Iran.

4. Afshin Saidi $(\mathrm{MPH})$.

Liver \& Digestive Research Center,

5. Namam Ali Azadi (PhD).

Biostatistics Department, School of Public Health, Iran University of Medical Sciences,

Tehran, Iran.

6. Abdorrahim Afkhamzadeh (MD, MPH).

Associate Professor of Community Medicine,

Social Determinants of Health Research Center, Research Institute for Health Development,

1,2,4,6: Kurdistan University of Medical Sciences, Sanandaj, Iran. 